\title{
Authentic Followership: Criticism of the Authentic Followership Models
}

\author{
Triyo Utomo* \\ Faculty of Psychology of Universitas Airlangga, Surabaya, Indonesia \\ triyo.utomo-2020@psikologi.unair.ac.id

\section{Seger Handoyo} \\ Faculty of Psychology of Universitas Airlangga, Surabaya, Indonesia

\section{Fajrianthi} \\ Faculty of Psychology of Universitas Airlangga, Surabaya, Indonesia
}

\begin{abstract}
Scholars have begun to shift their focus from leadership to followership. The results of several studies indicate that followership has several positive impacts. One type of followership that exists is authentic followership. Several scholars have created several authentic followership models that have been published in journals. In this paper, we will discuss the strengths and weaknesses of existing authentic followership models. The method used in this paper is by conducting a scoping review to answer the research objectives. A scoping review is a method for synthesizing and categorizing research results based on the literature review that has been carried out. Furthermore, the analysis used in this scoping review is thematic analysis. As a result, each authentic followership model has its own strengths and weaknesses. In addition, based on the perspective of the underlying theory, the three existing authentic followership models can be divided into two perspectives. The two perspectives are state and trait perspectives. This paper will also discuss the criticism of the state and trait perspectives. The practical implication of this paper is that there is a need to develop an authentic followership model based on the results of existing research.
\end{abstract}

Keywords: Authentic, Critics, Followership, State, Trait

\footnotetext{
${ }^{*}$ Corresponding author
} 


\section{Introduction}

The topic of followership still gets less attention from scholars when compared to leadership. Many studies focus more on leadership qualities and ignore follower qualities. As a result, followership studies have less scientific theoretical literature when compared to leadership (Budiarto, 2005). The literature regarding the existence and importance of the concept of followership was first presented by Kelley (1988) in Harvard Business Review. Furthermore, followership has become an interesting topic for discussion because followers support the success of organizational functioning (Chaleff, 2009; Kelley, 1992; Oc \& Bashshur, 2013; Robert Kelley, 1988; Schindler, 2015; Uhl-Bien et al., 2014; Zawawi et al., 2012; Zoogah, 2014).

Scholars have begun to shift their focus of attention from the topic of leadership to followership for several reasons. First, there were social changes in America and other countries due to the economic crisis in the early 1980s. As a result, many organizations are leaner in structure and some of the responsibility of the leader is delegated to followers. Second, social scientists began to discuss the active role of followers in the twentieth century. Corporate organizations in America experienced a golden age after World War II. American companies promise long-term job security to their employees in exchange for their loyalty to the company. This happened because the economic conditions at that time were stable. The stability of these conditions changed in the early 1980 s as the American industry experienced a crisis. As a result, there was a downsizing trend in the 1980s and 1990s. This condition makes the organizational structure flatter, power and responsibility are delegated to a group of people, including to followers. Leaders also expect initiative and risk taking by their followers. The loss of the psychological contract and the organizational pressure brought on by the downsizing trend of the 1980s and 1990s were seen as opportunities for employees to form a new psychological contract in the form of partnership roles with their leaders. In addition, scholars began to recognize and discuss followership in the 20th century (Baker, 2007).

The initial view of the active followership theory was started in 1955 by Hollander and Webb (1955), who argued that leaders and followers are not contradictory positions, instead seeing them as interdependent. Hollander and Julian (1969) conducted a review of the research results and concluded that leadership includes a two-way relationship between leaders and followers. In addition, Harold (1977) uses laboratory research to show how each party can influence the other in the leader-follower relationship. In 1988, followership was stated by Kelley (1988) as worthy of respect and research through his work "In Praise of Followers".

The results of several studies indicate that followership has several positive impacts. A better understanding of the concept of followership has the effect of improving training and organizational performance. Followership has a positive effect on training performance because the individual being trained by the leader will know how to act and behave as a follower (Crossman \& Crossman, 2011). Followership can also increase organizational commitment (Lee \& Reade, 2018), increase the perception of job satisfaction (Jin et al., 2016), have a direct positive impact on 
decision-making ability (Amin et al., 2020), and also have a positive impact on shared values (Fontoura \& Coelho, 2020). In addition, followership is positively related to follower creativity (Kong dkk., 2019; Wang \& Liang, 2020), and has an indirect positive relationship with follower work engagement (Veestraeten et al., 2020).

In the context of the literature on followership, authentic followership is categorized into prescriptive groups. The meaning of the word prescriptive is that authentic followership theory focuses on the ideal behavior that must be displayed by followers (Crossman \& Crossman, 2011). Several scholars have created several authentic followership models that have been published in journals (de Zilwa, 2016; Gardner dkk., 2005; Oc dkk., 2020). Although there are already several published authentic followership models, it is better for these authentic followership models to be critically examined to gain a more complete understanding of what their strengths and weaknesses are. Furthermore, the literature review is also useful for seeing the theoretical basis of existing authentic followership models.

\section{Theoretical Framework}

In the following sections we discuss three existing frameworks for authentic followership models.

1. A self-based model of authentic leader and follower development by Gardner et al. (2005).

This model was created to develop Luthans and Avolio's (2003) theory of authentic leadership development, by providing a deeper understanding of the self-based perspective of authentic leaders and followers. Gardner et al. (2005) identified the need to include followers as a key element in building a leadership model, as stated by Howell and Shamir (2005). Model development by Gardner et al. (2005) was carried out by first defining the constructs of authenticity, authentic leadership, and authentic followership. Authentic followership itself is defined by Gardner et al. (2005) as a process of following with self-awareness in the form of values, identities, emotions, and motives or goals, so as to produce selfregulation that is realized through internalization of values, processing of balanced information, objective relationships, and authentic behavior (actions guided by individual values, beliefs, and feelings). This model also provides an overview of the conceptual framework and is followed by a more in-depth discussion of authentic leadership and its impact on followers. Then, several propositions are proposed that can be studied through the discussion process.

The theoretical basis used for this model is derived from the self and identity literature. Authenticity is defined as being honest with oneself, so that the literature on self and identity is very appropriate and informative for developing models. Gardner et al. (2005) view the personal history of leaders and trigger events as antecedents to the development of authentic leadership. According to this model, triggering events serve as a catalyst to increase the leader's selfawareness, which can be perceived both positively and negatively. A key factor contributing to the development of authentic leadership is selfawareness, or the leader's personal intuitive understanding. Self-awareness is related to self-reflection, such as reflection through introspection, so that authentic leaders gain clarity and conformity with core values, identities, emotions, motives, and goals. The 
second most important component of authentic leadership development is self-regulation. Based on this model, several features related to the selfregulation process are distinguished, including internalized regulation, balanced information processing, authentic behavior, and relational transparency.

The main view of this model is that authentic leaders actively and continuously become models for followers through words and actions that reflect self-awareness, balanced processing, transparency, and authentic behavior. Furthermore, authentic leaders serve as inputs for the development of authentic followers. Like leaders, this model states that the follower's personal history coupled with certain triggering events is the beginning of the emergence of authentic followership. Furthermore, when followers see the leader display a self-aware understanding and engage in transparent decision-making that reflects integrity and a commitment to core ethical values, they develop trust in the leader, thereby encouraging openness and authentic behavior. Over time, this could become the group norm for an ethical culture. This model also asserts that authentic leader integrity is demonstrated, resulting in high trust, attachment, and well-being among followers. It will encourage continued follower performance. Organizational culture also plays an important role in the model proposed by Gardner et al. (2005). An inclusive, caring, ethical, and strengths-based organizational culture can play a role in the development of authentic leaders and followers. Organizational culture acts as a context that can influence and is also influenced by authentic leadership and authentic followership. Furthermore, the contribution of authentic organizational members can encourage and maintain a positive organizational climate.

2. Authentic followership model by de Zilwa (2014).

The authentic followership model by de Zilwa (2014) is based on the case of the global financial crisis that occurred in 2008 in several companies, by analyzing how and why authentic followership can prevent or reduce financial stress and damage to the company's reputation. Furthermore, de Zilwa (2014) proposes and explains a new conceptual framework for authentic followership. Empirical testing of the authentic followership construct has not yet been carried out. However, the results of this work can identify the contribution of authentic followership to leadership effectiveness and organizational performance, as well as identify conditions that must be avoided in order for authentic followership to emerge. de Zilwa (2016) explains in stages how the followership model is structured. First, it provides an overview of the authentic followership construct to help the reader understand how the proposed proposition works. Second, it presents 3 positive outcome propositions that can arise through authentic followership. Third, it explains the practical impact of authentic followership on followers, leaders, and companies.

De Zilwa's (2016) followership model is different from the model by Gardner et al. (2005). de Zilwa (2016) calls it an authentic followership model. Authentic followership, according to de Zilwa (2016), is a followership process consisting of components of the individual's psychological capacity for authenticity, strong reciprocal relationships between leaders and followers, and the existence of a positive 
organizational culture. The main opinion of the authentic followership model is that authentic followership is a relational concept. The basis for authentic followership must be the individual's capacity for authenticity. Although individuals already have this capacity, they are not able to display authentic followership behavior (eg, suggesting innovations or criticizing the leader's decisions) if they are not equipped with the other two elements. The two elements are the relationship of followers to the leader and the context or organizational culture in which the relationship between followers and leaders occurs. The new framework for authentic followership is a comprehensive and powerful model because it consists of 3 important components (individual, dyadic relationship, and organization) and describes the process of interaction between each component. The key features of the new authentic followership construct are circular models and non-linear feedback. The meaning of non-linear feedback is that each component that builds authentic followership interacts with each other on an ongoing basis, which allows authentic followership to grow and survive. Furthermore, the new authentic followership construct is not a linear causal model.

The first component of the authentic followership model is the individual follower, namely how the individual thinks and behaves, related to the psychological capacity or mind-set for authenticity. This capacity requires 4 attributes, namely awareness, unbiased information processing, action, and relational orientation. The second component is the dyadic relationship between leader and follower, which relates to followers' secure attachment to the leader. The third component of the authentic followership model is the context or company setting, which is a characteristic of the company's organization. This includes a positive organizational culture and political conditions. A positive organizational culture is characterized by cohesion and cooperation as well as positive emotions such as optimism, hope, strength, trust, and appreciation. Organizational culture in de Zilwa's (2016) model acts as the context for the relationship between leaders and followers.

3. Followers felt authenticity model by Oc et al. (2020).

The follower felt authenticity model by Oc et al. (2020) is compiled by first explaining about authenticity, which can be influenced by several factors. These factors are leader humility, authenticity of leader humility, and follower vulnerability. Furthermore, Oc et al. (2020) discusses the impact of leader humility on follower vulnerability, the moderating role of leader humility authenticity, and the effect of follower vulnerability on followers' felt authenticity. Then, four hypotheses were proposed which were tested empirically in the field. The research method used is correlation research and experiments, through 4 research processes (study). The first research process (study 1 ) was carried out with correlation to test the four hypotheses proposed. The second research process (study 2) used experimental methods to determine the causal effect by manipulating the leader's humility variable and testing its impact on followers' vulnerability. This is done to test hypothesis 1 . The third research process (study 3) uses experimental methods to determine the impact of follower vulnerability on followers' felt authenticity (to test hypothesis 3). The fourth research 
process (study 4) tested all hypotheses and tested whether the authenticity of leader humility moderated the impact of leader humility on followers' vulnerability, which in turn had an impact on followers' felt authenticity. The fourth research was conducted with an experimental design. The four research processes that have been carried out provide results that support all proposed hypotheses.

The followership model of Oc et al. (2020) developed a mediation moderation model that theorizes about how and under what conditions a leader's humility relates to followers' felt authenticity. Follower perceived authenticity is described by Oc et al. (2020) as a condition for followers to be able to express themselves according to their thoughts and feelings based on the situation at hand. This model explains that followers feel less vulnerable when the leader expresses humility, and that this relationship is weakened when the authenticity of the leader's humility declines. In addition, this model states that follower vulnerability is negatively related to followers' feeling of authenticity. The lower the vulnerability of the follower, the more the follower can feel authenticity. In general, this model reveals that the indirect effect of leader humility on followers' felt authenticity through follower vulnerability is moderated by the authenticity of leader humility, so the indirect relationship is stronger for leaders whose humble behavior is more authentic.

\section{Research Methodology}

The method used in this research is scoping review. In addition, the analysis used is thematic analysis. The literature search was carried out using the Scopus, Sage, Proquest, Science Direct, Emerald Insight, JSTOR, Springer
Link All Journals, Ebscohost, and Garuda databases. In the early stages of searching for journal articles, 331 articles were obtained from 2000 onwards using the keywords "Authentic Followership", "Authentic Follower", and "Follower Authenticity". The number of appropriate articles based on the results of the review on the title and abstract is 17 articles. Next, the 17 articles are read in full paper to find articles that are relevant to the research question. This process generates 3 relevant articles. In more detail, the process carried out can be described by the following prism flow chart (figure 1 ).

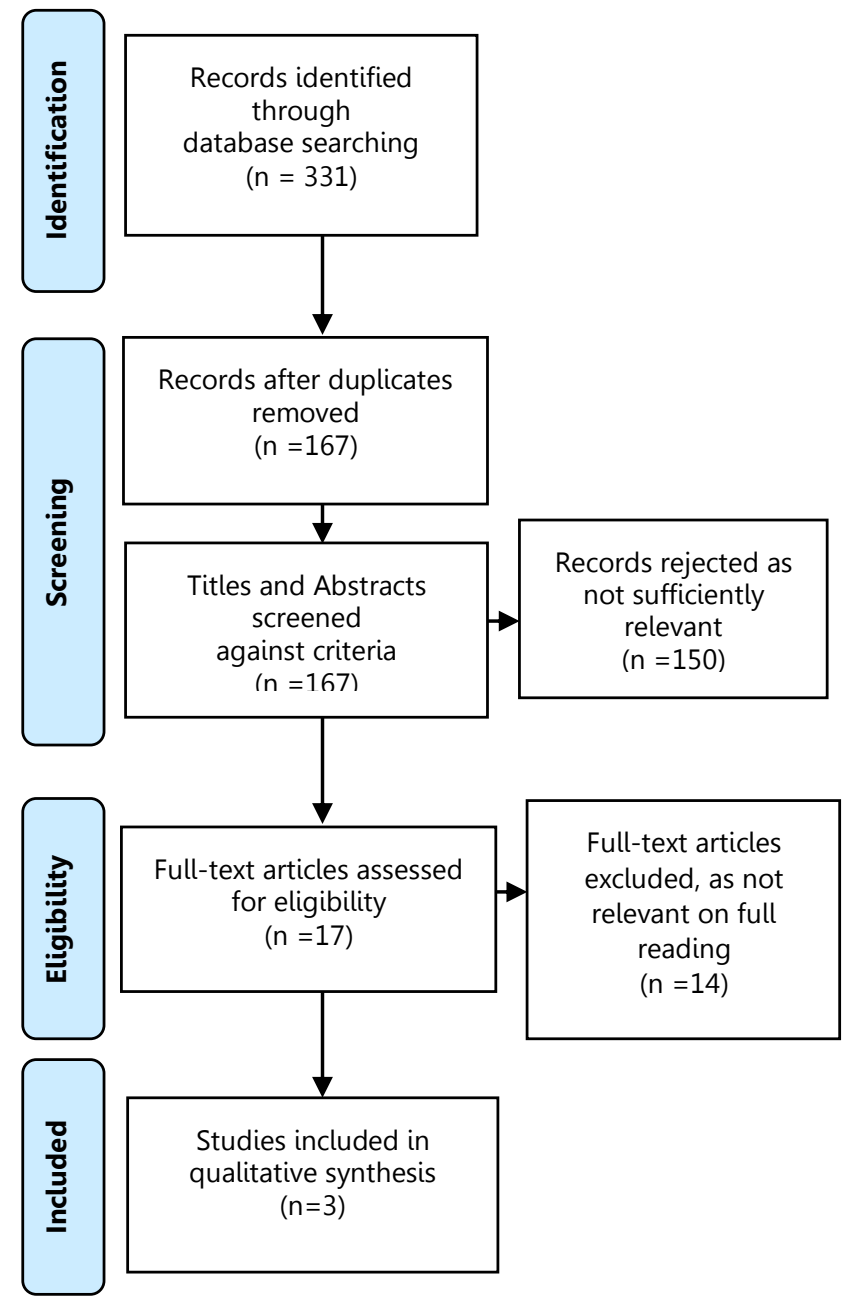

Figure 1. Prism flow chart of the article selection process 


\section{Themes}

\section{Strengths and weaknesses of authentic followership models}

Based on existing authentic followership models (de Zilwa, 2016; Gardner et al., 2005b; Oc et al., 2020), there are some things that can be evaluated. First, the model proposed by Gardner et al. (2005) saw the concept of authentic followership as an integral part and consequence of authentic leadership (did not see authentic followership as a separate concept). In addition, the model is only based on several propositions from the literature review that has been carried out. However, Gardner et al. (2005) were the first scholars to create an authentic followership model. Second, the model proposed by de Zilwa (2016) does view authentic followership as a separate concept. However, de Zilwa (2016) is unsure of the limitations of his model. De Zilwa (2016) also mentions that his model has an unclear time dimension regarding how long leaders and followers must work together so that followers believe in their leaders so that they can display authenticity. de Zilwa's (2016) authentic followership model is also built from propositions based on the results of a literature review. Criticisms that can be made of the model by Gardner et al. (2005) and de Zilwa (2016), namely that the two models are only based on the proposition of the results of a literature review and have not been tested empirically. In addition, a weakness of the literature review proposition is that Gardner et al. (2005) and de Zilwa (2016) assume that the reader has sufficient knowledge and intellectual background to understand the implicit meaning of the propositions proposed, so that there is a possibility that the implicit message of the proposition can not be captured by the reader. The next weakness is that the proposition of the results of a literature review has a tendency to predict outcomes that go beyond the scope of the objectives and the research methodology used (Avan \& White, 2001).

Evaluation was also carried out on the model proposed by Oc et al. (2020). The follower felt authenticity model by Oc et al. (2020) is indeed compiled based on the results of empirical studies. However, the authors found weaknesses based on research reports. The weakness is that Oc et al. (2020) explains that the definition of follower felt authenticity is only limited to certain work situations that are not related to the leader. This definition differs from Gardner et al. (2005) and de Zilwa (2016) descriptions of authentic followership, who attribute it to leaders. The second weakness is that there is an inconsistency between the measuring tools used to reveal followers' felt authenticity and the theoretical basis of authenticity described in the literature review. The authenticity discussed in the theory section is indeed based on the theory of state authenticity by Sedikides et al. (2017). However, the measuring instrument used to measure follower felt authenticity was not developed from the theory of state authenticity by Sedikides et al. (2017). The follower felt authenticity measurement tool was taken from the inauthentic measurement tool in the workplace by Erickson and Ritter (2001). Erickson and Ritter (2001) created a tool for measuring inauthenticity in the workplace based on the sociological theory of feelings and emotions (Hochschild, 1975).

\section{The dichotomy of state authenticity and trait authenticity perspectives}

The next critique relates to the theoretical perspective applied to 
authentic followership models. When viewed from the perspective of the theory used, broadly speaking, the three existing authentic followership models are divided into two groups. The first group uses a state-based theory of authenticity perspective by Sedikides et al. (2017). The second group uses a trait-based theory of authenticity by Kernis (2003). The perspective of the state-based theory of authenticity is found in the follower felt authenticity model by Oc et al. (2020). While the authenticity theory perspective based on traits is used by Gardner et.al (2005) and de Zilwa's (2016) authentic followership model.

The dichotomy between state and trait theory perspectives is still controversial in psychological studies. In fact, Allen and Potkay (1981) call the perspective difference between state and trait theory arbitrary because it does not have a conceptual basis in terms of methodology. In addition, the concept of state and trait theory contains ambiguity and complexity based on the underlying concepts (Fridhandler, 1986). The dichotomy between the perspective of state authenticity and trait authenticity has just emerged in the writings of Sedikides et al. (2017) and Oc et al. (2020). As for Kernis (2003), Gardner et al. (2005), and de Zilwa (2016), they themselves did not mention the authenticity they used as trait authenticity.

Based on the perspective of the underlying theory of authenticity, the theory of Kernis (2003) has advantages when compared to Sedikides et al. (2017). Kernis (2003) definition of authenticity is more comprehensive, because it includes a variety of individual daily activities along with the 4 underlying components (awareness, objective information processing, actions, and relationships). While the definition of Sedikides et al. (2017) about authenticity is only limited to individual responses (emotions, cognitions, and actions) to the current situation.

\section{Conclusion}

Based on the results of the evaluation of the previous authentic followership models, it should be necessary to create a new authentic followership model based on the theory of authenticity by Kernis (2003) because it is more comprehensive in explaining authenticity. In addition, the authentic followership model to be built is suggested to refer to the model of Gardner et al. (2005). This is based on several considerations. First, the model of Gardner et al. (2005) is the only model (of the existing model) that links authentic leadership with authentic followership. Second, the results of a literature review show that there is indeed an effect of authentic leadership on authentic followership (Tak et al., 2019; Yagil \& Medler-Liraz, 2014). Third, the definition of Gardner et al. (2005) of authentic followership is classified as more complete when compared to other scholars. 


\section{References}

Allen, B. P., \& Potkay, C. R. (1981). On the arbitrary distinction between states and traits. Journal of Personality and Social Psychology, 41(5), 916-928.

https://doi.org/10.1037/00223514.41.5.916

Amin, B., Hamidah, \& Gunawan, K. (2020). The influence of transformational leadership, power distance, and followership on the decision making capability. Management Science Letters, 10(16), 3915-3922.

https://doi.org/10.5267/j.msl.2020. 7.019

Avan, B. I., \& White, F. (2001). The proposition: An insight into research. Journal of the Pakistan Medical Association, 51(1), 49-53.

Baker, S. (2007). Followership: The Theoretical Foundation of a Contemporary Construct. Journal of Leadership \& Organizational Studies, 14(1), 50-60. https://doi.org/10.1177/00028312 07304343

Budiarto, Y. (2005). Followership : Sisi Lain Kepemimpinan Yang terlupakan. Jurnal Psikologi, 3(1), 19-23.

Chaleff, I. (2009). The Courageous Follower: Standing up to \& for Our Leaders (3rd ed., Vol. 4). Berrett-Koehler.

Crossman, B., \& Crossman, J. (2011). Conceptualising followership - a review of the literature. Leadership, 7(4), 481-497. https://doi.org/10.1177/17427150 11416891

de Zilwa, D. (2014). A New Conceptual Framework for Authentic Followership. In L. M. Lapierre \& M. K. Carsten (Eds.), Followership: What is it and why do people follow? (pp. 47-72). Emerald
Group Publishing Limited.

https://subzero.lib.uoguelph.ca/lo gin?URL=?url=https://www.proqu est.com/docview/2130855164?acc ountid $=11233 \% 0$ Ahttps://oculgue.primo.exlibrisgroup.com/open url/01OCUL_GUE/01OCUL_GUE:G UELPH?

\&genre = book\&issn $=$ \&title $=$ Follo wership\&volume $=$ \&issue $=$ \&date $=$ 2014\&atitl

de Zilwa, D. (2016b). The strengths and capacities of Authentic Followership. Leadership \& Organization Development Journal, 37(3), 310-324. https://doi.org/http://dx.doi.org/1 0.1108/LODJ-01-2014-0010

Erickson, R. J., \& Ritter, C. (2001). Emotional labor, burnout, and inauthenticity: Does gender matter? Social Psychology Quarterly, 64(2), 146-163. https://doi.org/10.2307/3090130

Fontoura, P., \& Coelho, A. (2020). The influence of supply chain leadership and followership on organizational performance: An empirical study on a Portuguese energy supplier. Baltic Journal of Management, 15(3), 333-353. https://doi.org/10.1108/BJM-012019-0012

Fridhandler, B. M. (1986). Conceptual Note on State, Trait, and the State-Trait Distinction. Journal of Personality and Social Psychology, 50(1), 169-174.

https://doi.org/10.1037/00223514.50.1.169

Gardner, W. L., Avolio, B. J., Luthans, F., May, D. R., \& Walumbwa, F. (2005). "Can you see the real me?" A selfbased model of authentic leader and follower development. Leadership Quarterly, 16(3), 343372.

https://doi.org/10.1016/j.leaqua.2 
005.03 .003

Herold, D. M. (1977). Two-Way

Influence Processes In Leader-

Follower Dyads. Academy of

Management Journal, 20(2), 224-

237.

https://doi.org/10.5465/255396

Hochschild, A. R. (1975). The Sociology

of Feeling and Emotion: Selected

Possibilities. Sociological Inquiry,

45(2-3), 280-307.

https://doi.org/10.1111/j.1475-

682X.1975.tb00339.x

Hollander, E P, \& Webb, W. B. (1955).

Leadership, followership, and friendship: an analysis of peer nominations. Journal of Abnormal and Social Psychology, 50(2), 163167.

https://doi.org/10.1037/h0044322

Hollander, Edwin P., \& Julian, J. W. (1969). Contemporary trends in the analysis of leadership processes. Psychological Bulletin, 71(5), 387-397.

https://doi.org/10.1037/h0027347

Howell, J. M., \& Shamir, B. (2005). The role of followers in the charismatic leadership process: Relationships and their consequences. Academy of Management Review, 30(1), 96112.

https://doi.org/10.2307/20159097

Jin, M., McDonald, B., \& Park, J. (2016).

Followership and job satisfaction in the public sector: The moderating role of perceived supervisor support and performance-oriented culture. International Journal of Public Sector Management, 29(3), 218237.

https://doi.org/10.1108/IJPSM-052015-0101

Kelley, R. E. (1992). The Power of Followership: how to create leaders people want to follow, and followers who lead themselves.
Doubleday/Currency.

Kernis, M. H. (2003). Toward a

conceptualization of optimal self-

esteem. Psychological Inquiry,

14(1), 1-26.

https://doi.org/10.1207/S1532796

5PLI1401_01

Kong, M., Xu, H., Zhou, A., \& Yuan, Y. (2019). Implicit followership theory to employee creativity: The roles of leader-member exchange, self-efficacy and intrinsic motivation. Journal of Management \& Organization, 25(1), 81-95. https://doi.org/DOI: 10.1017/jmo.2017.18

Lee, H.-J., \& Reade, C. (2018). The role of Yin-Yang leadership and cosmopolitan followership in fostering employee commitment in China: A paradox perspective. Cross Cultural and Strategic Management, 25(2), 276-298. https://doi.org/10.1108/CCSM-122016-0216

Luthans, F., \& Avolio, B. (2003). Authentic Leadership Development. In \& R. E. Q. In K. S. Cameron, J. E. Dutton (Ed.), Positive organizational scholarship (pp. 241-261). Barrett-Koehler.

Oc, B., \& Bashshur, M. R. (2013). Followership, leadership and social influence. Leadership Quarterly, 24(6), 919-934. https://doi.org/10.1016/j.leaqua.2 013.10 .006

Oc, B., Daniels, M. A., Diefendorff, J. M., Bashshur, M. R., \& Greguras, G. J. (2020a). Humility breeds authenticity: How authentic leader humility shapes follower vulnerability and felt authenticity. Organizational Behavior and Human Decision Processes, 158, 112-125. 
https://doi.org/https://doi.org/10. 1016/j.obhdp.2019.04.008

Robert Kelley. (1988). In Praise of

Followers. Hbr.Org.

https://hbr.org/1988/11/in-praiseof-followers

Schindler, J. H. (2015). Followership: What It Takes to Learn (J. Phillips \& S. Gully (eds.); 1st ed.). Business Expert Press.

https://doi.org/10.1787/97892642 01170-5-en

Sedikides, C., Slabu, L., Lenton, A., \& Thomaes, S. (2017). State authenticity. Current Directions in Psychological Science, 26(6), 521525.

https://doi.org/10.1177/09637214 17713296

Tak, J., Seo, J., \& Roh, T. (2019). The influence of authentic leadership on authentic followership, positive psychological capital, and project performance: Testing for the mediation effects. Sustainability (Switzerland), 11(21). https://doi.org/10.3390/su112160 28

Uhl-Bien, M., Riggio, R. E., Lowe, K. B., \& Carsten, M. K. (2014). Followership theory: A review and research agenda. Leadership Quarterly, 25(1), 83-104. https://doi.org/10.1016/j.leaqua.2 013.11.007

Veestraeten, M., Johnson, S. K., Leroy, H., Sy, T., \& Sels, L. (2020). Exploring the Bounds of Pygmalion Effects: Congruence of Implicit Followership Theories Drives and Binds Leader Performance Expectations and Follower Work Engagement. https://doi.org/10.1177/15480518 20980428
Wang, L., \& Liang, X. (2020). The influence of leaders' positive and implicit followership theory of university scientific research teams on individual Creativity: The mediating effect of individual selfcognition and the moderating effect of proactive personality. Sustainability (Switzerland), 12(6). https://doi.org/10.3390/su120625 07

Yagil, D., \& Medler-Liraz, H. (2014). Feel free, Be Yourself: Authentic Leadership, Emotional Expression, and Employee Authenticity. Journal of Leadership and Organizational Studies, 21(1), 5970.

https://doi.org/10.1177/15480518 13483833

Zawawi, A. A., Kamarunzaman, N. Z., Hussin, Z., \& Campbell, J. (2012). The power of followership: Leaders, who are you leading? SHUSER 2012 - 2012 IEEE Symposium on Humanities, Science and Engineering Research, August 2014, 195-199. https://doi.org/10.1109/SHUSER.2 012.6268851

Zoogah, D. B. (2014). Strategic followership: How followers impact organizational effectiveness. In Strategic Followership: How Followers Impact Organizational Effectiveness (1st ed.). Palgrave Macmillan. https://doi.org/10.1057/97811373 54426 